\title{
Öğretmen Adaylarının Çevre Etiği Yaklaşımlarının Yordayıcısı Olarak Eleştirel Düşünme Eğilimlerinin İncelenmesi
}

\begin{abstract}
Mehpare SAKA*
Öz

$\mathrm{Bu}$ çalışmada öğretmen adaylarının eleştirel düşünme eğilimlerinin çevre etiği yaklaşımları üzerindeki etkisi araştırılmıştır. Araştırma modelini genel tarama modellerinden ilişkisel tarama modeli oluşturmaktadır. Araştırmanın çalışma grubu iki devlet üniversitesinin eğitim fakültesinde öğrenim gören fen bilgisi, okul öncesi ve sınıf öğretmenliği bölümlerinde okuyan toplam 641 öğretmen adayından oluşmaktadır. Veri toplama araçları olarak "Kişisel Bilgi Formu", "Kaliforniya Eleştirel Düşünme Eğilimleri Ölçeği" ve "Çevre Etiği Yaklaşımları Ölçeği" kullanılmıştır. Verilerin analizinde SPSS- 17 paket programı kullanılarak öncelikle regresyon modelini oluşturmak amacıyla Pearson Momentler Çarpım Korelasyon katsayısından yararlanılmıştır. Daha sonra öğretmen adaylarının eleştirel düşünme eğilimlerinin çevre etiği yaklaşımlarını yordayıp yormadığını tespit etmek amacıyla çoklu regresyon analizi yapılmıştır. Yapılan analizlere göre eleştirel düşünme eğilimlerinden analitiklik boyutunun her üç çevre etiği yaklaşımı üzerinde yordayıcı etkisinin olduğu tespit edilmiştir. Bununla birlikte diğer bazı eleştirel düşünme eğilimlerinin de farklı çevre etiği yaklaşımları üzerinde yordayıcı etkisinin olduğu, eleştirel düşünme eğiliminden açık fikirliliğin çevre etiği yaklaşımları üzerinde yordayıcı bir etkisinin olmadığ 1 tespit edilmiştir.
\end{abstract}

Anahtar Kelimeler: Çevre etiği, eleştirel düşünme eğilimi eğilimi, öğretmen aday1.

\section{A Study of Pre Service Teacher' Critical Thinking Dispositions as Predictors of Environmental Ethics Approaches}

\begin{abstract}
This study deals with the effects of pre service teachers' critical thinking dispositions on environmental ethics approach. Its study model is relational screening model. Study population involves 641 pre service teacher who are studying science, preschool and primary school teaching at Faculty of Education of two state universities. Data collection tools are "Personal Information Form", "California Critical Thinking Disposition Inventory" and "Environmental Ethics Approaches Scale". SPSS-17 program was used in data analysis and Pearson product-moment correlation model was used in order to establish a regression model. Then, multiple regression
\end{abstract}

\footnotetext{
* Dr., Trakya Üniversitesi, Eğitim Fakültesi, Fen Bilgisi Eğitimi Bölümü, msaka@trakya.edu.tr
} 
analysis was carried out in order to find out whether pre service teachers' critical thinking dispositions predicted their environmental ethics approach. Analysis indicated that being analytic, one of the critical thinking dispositions predicted all three environmental ethics approaches. It was also found out that several other critical thinking dispositions predicted various environmental ethics approaches while open-mindedness had no predictor effect on environmental ethics approaches.

Keywords: Environmental ethics, critical thinking disposition, teacher candidate.

\section{GİİŞ}

Başlangıcı daha eskilere dayanmasına rağmen özellikle Alpo Leopold'un toprak etiği yaklaşımı ile daha fazla kabul görmeye başlayan çevre etiği; insan ve çevre arasındaki ilişkiyi anlamaya çalışarak (Jardin, 2006; Kılıç, 2008; Sandler, 2013) insanların belli kurallar çerçevesinde doğa ve çevreye geçişini sağlayan ve düzenleyen sistematik bir değerlendirme (Cochrane, 2006; ECCAP, 2012; Ertan, 2004, Huying, 2004) olarak ifade edilmektedir. Düşünce ve davranışlarımızı belirleyen etik yaklaşımlar (Ertan, 2004) insanın çevre ile olan ilişkisinde de önemli bir çerçeve oluşturmaktadır (Gül, 2013). Çevre etiği çevresel değerler kapsamında iyi ve kötü çevrecilik kavramının ne olduğu sorusunun üstesinden gelmeye çalışırken bir yandan da doğrudan bireysel şekilde gelişmiş değerler sistemi olarak yönetilen insan davranışları ile direkt ilişki içindedir (Raı ve Sırrma, 2011). Aynı zamanda çevre etiği ekolojiyi anlamlandırmak ve bir varlığın değerini vurgulamakta oldukça büyük öneme sahiptir (ECCAP, 2012). Uygulamalı etiğin bir alt dalı olarak ifade edilen çevre etiği, insanın doğa ile ilişkisinin nasıl olması gerektiğini sorgulayarak, doğru davranışın ne olması gerektiğini belirlemeye çalışırken (Amerbauer, 1998, akt. Kılıç, 2008) insanın doğayla harmoni içinde yaşamasını amaçlar (Huying, 2004).

20. yüzyılın ikinci yarısı ile birlikte ortaya çıkan birçok çevre felaketi, çevre etiğine olan ilgiyi artırarak sistematik bir düzene girmesini sağlamıştır. Bununla birlikte bir çevre krizinin olup olmadığına dair çeşitli düşünceler çerçevesinde özellikle 1980'lerde bilimsel bir niteliğe kavuşan (Cochrane, 2006) çevre etiği ile ilgili farklı bakış açıları da bulunmaktadır. Demirin bulunması ile birlikte sanayi devrimine kadar devam eden süreç insan merkezci (antroposentrik) yaklaşımın benimsendiği dönemi içermektedir. Özellikle 16. ve 17. Yüzyılda Bacon, Descartes ve Newton gibi bilim adamlarının dile getirdiği gibi doğanın insanın emrine sunulduğu düşüncesi (Gül, 2013) özellikle sanayi devrimiyle birlikte daha şiddetli hale gelmiştir. Bu dönemde insan doğaya karşı daha acımasız hale dönüşerek sınırsız kullanım ve sömürüyü benimsemiştir (Ertan, 2004). Ancak sanayi devrimi sonrası ile birlikte insan, çevreye zarar verdiği sürece kendisinin de bundan olumsuz etkilendiğini görmeye başlamıştır. Böylece insan merkezci yaklaşımın yanı sıra çevre ve insan arasındaki uyumun önemini vurgulayan öncelikle biyosentrik ve devaminda ekosentrik yaklaşımlar ortaya çıkmaya başlamıştır. Çevre etiğinin temel üç yaklaşımından biri olan antoposentrik çevre etiği, insan olmayan doğal varlıkları sadece insanların iyiliği için göz önünde bulundururken, biyosentrik yaklaşım hem insanı hem de insan dışında kalan diğer canlıları hak sahibi yapmıştır. Diğer bir çevre etiği yaklaşımı olan ekosentrizmde ise dünyada canlı cansız bütün varlıkları içine alan en geniş etik anlayışını temsil etmektedir (Anemiya ve Macer, 1999; Ertan, 2004; Jardin, 2006; Kılıç, 2008).

Bireyin doğal çevresiyle olan ilişkisine vurgu yapan çevre okuryazarlığı, bireylerin çevreye yönelik bilgi, beceri, tutum ve çevre sorunlarına yönelik sorumluluk alarak karar alma motivasyonuna sahip olma amacını güder (Karatekin ve Aksoy, 2012; Roth, 1992). Artık var olan çevre sorunları ile birlikte bu sorunların üstesinden gelerek çevreye yönelik olumlu davranışların kazandırılarak (Gül, 2013; Jardin, 2006) çevre okuryazarı bireyler yetiştirmede, çevre eğitimi ve etiğin dahil edildiği çevre etiği eğitiminin önemi ortaya çıkmaktadır. Çevre etiği 
eğitimi ile bireyin çevresel krizlerde nasıl bir sorumluluk içinde olduğu dikkate alınarak özellikle sürdürülebilirlik konusunda farkındalık yaratarak, çevre sorunlarının çözümü ve önlenmesi için bilgi ve becerilerin artırlarak, bireysel ve toplumsal çalışmalara yönlendirmeler teşvik edilmelidir. Ayrıca çevre problemlerine yönelik değer ve tutumların gelişimi sağlanırken, etkili beceri ve davranışların kazandırılması gerekir (ECCAP, 2012). Bu düşünce sistemlerinin oluşmasında bireyin neye inandığına karar vermek üzerine odaklanılmış düşüncenin yansitılması, sorumluluğunun alınması olarak tanımlanan eleştirel bakış açısına ne düzeyde sahip olduğunun önemi ortaya çımaktadır. Yaşam boyu öğrenmenin sürekli vurgulandığı günümüz eğitiminde özellikle bireylerin problem çözme becerisi ve yaratıcıllğını önemli derecede etkileyen eleştirel düşünme becerisine sahip olması daha da önem kazanmıştır (Seferoğlu ve Abıyık; 2006). Eleştirel düşünme hem felsefe hem psikoloji hem de eğitimsel alanlarda ele alınan geniş bir kavramdır. Eğitimde Bloom, Gagne, Perkins ve Renzulli gibi önemli eğitimciler öğrencilerin problem çözmek, karar vermek ve kavram öğrenmek için doğrudan sorumluluk alma becerilerine sahip olmaları gerektiğini ifade etmektedirler (Sternberg, 1986). Üst bilişsel becerinin, eleştirel düşünmenin temelini oluşturduğu ve ikisi arasında anlamlı düzeyde ilişki olduğunu gösteren pek çok çalışma (Halpern, 1998; Kogut 1996; Schoen, 1983) öğrenen merkezli öğretimde eleştirel düşünme becerisinin kazandırılmasının önemini ortaya çıarmaktadır. Eleştirel düşünmeye yönelik yapılan bir tanımlamadaki (Ennis, 1987, 1991; Lipman, 1988) ortak nokta bireyin düşüncesini dikkatli bir şekilde kontrol altına almayı sağlayacak yetenek, özel beceri ve anlayışları geliştirme yoluyla insan düşünmesinde kaliteyi geliştirme problemidir. Bireylerin bu becerilere sahip olabilmesi içinde eğitimin önemli bir unsuru olan öğretmenlerin eleştirel düşünmeyi benimseyerek kendi yaşamlarında kullanabilme becerisine sahip olması gerekir (Demirel, 2004; Özden, 2005). Aynı şekilde giderek artan çevre sorunlarına karşı oluşturulan çevre eğitimi konusunda sadece programların değil öğretmenlerin de bakış açıları büyük öneme sahiptir. Aile ile başlayan ve formal olarak devam eden eğitim sürecinde yetişkinlerin ve özellikle öğretmenlerin çevresel bakış açılarını göz ardı etmemek gerekir. Bireydeki olumlu çevresel bakış açısını ortaya çıkarmada öğretmenlere büyük görev düşmektedir. Dolayısıyla bireylerin eleştirel bakış açısıyla çevreye yönelik daha doğru kararlar alarak davranışlar sergilemesinde de eğitimin ve dolayısıyla öğretmenlerin çevreye yönelik yaklaşımları ve ne kadar eleştirel düşünme becerisine sahip oldukları arasındaki ilişkinin dikkate alınması gerekir.

Dünya üzerinde bulunan canlı ya da cansız bütün varlıklar kendi içerisinde tutarlı bir sistemin parçasıdır. Bu sistemin devamlılığını sağlayarak, canlı ve cansız bütün varlıkların özerkliğine duyarlı (ekosentrik, biyosentrik) davranışlara sahip bireylerin sayısının artması dünyanın devamı ve yaşanabilirliği için büyük öneme sahiptir. Bireylerin tersi yöndeki antroposentrik yaklaşım türleri, ekosistemleri, yeryüzünü kapsayan diğer canlıların yaşam hakkını kabul etmedikleri anlamına gelebilir. Bu düşünce sistemlerinin oluşmasında bireyin neye inandığına karar vermek üzerine odaklanılmış düşüncenin yansıtılması, sorumluluğunun alınması olarak tanımlanan eleştirel bakış açısına ne düzeyde sahip olduklarının önemi ortaya çıkmaktadır. Bu doğrultuda çalışmanın amacı gelecek nesilleri yetiştirecek olan öğretmen adaylarının çevre etiği yaklaşımları (antroposentrik, biyosentrik, ekosentrik) ile bu yaklaşımların doğru bir şekilde şekillenmesinde etkili olduğu düşünülen eleştirel düşünme eğilimleri arasındaki ilişki durumu ve etkililik düzeyinin belirlenmesidir.

$\mathrm{Bu}$ amaç doğrultusunda (1) Öğretmen adaylarının çevre etiği yaklaşımları ne düzeydedir? (2) Öğretmen adaylarının eleştirel düşünme eğilimleri ne düzeydedir? (3) Öğretmen adaylarının eleştirel düşünme eğilimleri çevre etiği yaklaşımlarını yordamakta mıdır? sorularına cevap aranmıştır. 


\section{YÖNTEM}

Araştırmada öğretmen adaylarının çevre etiği yaklaşımlarını ve eleştirel düşünme eğilimlerini tespit etmek amaciyla, geçmişte veya mevcut olan durumu betimlemeyi amaçlayan (Çepni, 2010; Karasar, 2000) tarama türlerinden ilişkisel tarama modeli uygulanmıştır.

\section{1 Çalışma Grubu}

Araştırma 2014-2015 yılı eğitim-öğretim döneminde iki devlet üniversitesinin Eğitim Fakültesi fen bilgisi öğretmenliği, sınıf öğretmenliği ve okul öncesi öğretmenliğinde okuyan 641 öğretmen adayı ile gerçekleştirilmiştir (Tablo.1)

Tablo.1. Araştırmaya Katılan Çalışma Grubunun Özellikleri

\begin{tabular}{llll}
\hline & Kız & Erkek & Toplam \\
\hline Fen Bilgisi Öğrt. & 117 & 34 & 151 \\
Sinıf Ö̆ğret. & 194 & 55 & 249 \\
Okul Öncesi Öğrt. & 226 & 34 & 260 \\
Toplam & 546 & 123 & 641 \\
\hline
\end{tabular}

2.2 Veri Toplama Araçları

Araştırmada öğretmen adaylarının çevre etiği yaklaşımlarını tespit etmek için Çevre Etiği Yaklaşımları Ölçeği (Saka ve Sürmeli, 2013) kullanılmıştır. Ölçek 25 maddeden oluşmakta ve 5 'li likert tipinde olup "Kesinlikle katılmıorum" dan "Kesinlikle katıliyorum" şeklinde sıralanmaktadır. Ölçek antroposentrik, biyosentrik ve ekosentrik olmak üzere üç alt ölçekten oluşmaktadır ve ölçeğin bütününden değil her bir alt ölçekten ayrı ayrı puanlamalara göre değerlendirmeler yapılmaktadır. Antroposentrik ölçekte 8, biyosentrik ölçekte 11, ekosentrik ölçekte ise 6 madde bulunmaktadır. Ölçeğin Cronbach alpha güvenirlik katsayısı ölçek toplaminda .73, antroposentrikte .76, biyosentrikte .78, ekosentrikte .86 (Saka ve Sürmeli, 2013) olarak hesaplanmıştır.

Öğretmen adaylarının eleştirel düşünme eğilimlerini tespit etmek için de orijinali Facione, Facione ve Giancarlo tarafından 1998 yılında geliştirilen, Türkçeye geçerlik-güvenirlik çalışması Kökdemir (2003) tarafından yapılmış olan, Kaliforniya Eleştirel Düşünme Eğilimleri Ölçeği (KEDEÖ) kullanılmıştır. Ölçek 51 maddeden oluşmakta ve $6^{\prime}$ li likert tipinde olup, "Hiç katılmıyorum" dan "Kesinlikle katılmıyorum" şeklinde sıralanmaktadır. Ayrıca ölçek Analitiklik, Açık fikirlilik, Meraklılık, Kendine güven, Doğruyu arama, Sistematiklik olarak isimlendirilen 6 alt boyuttan oluşmaktadır. Maddelerden 22 tanesi ters yönde puanlanmakta ve maddelere katılma durumlarına göre her maddeye verilen puanlar toplanıp sonuç 306 puan üzerinden değerlendirilmektedir. Puanlama sonucunda 240'ın altında puan alanlar düşük, 240-300 arasinda puan alanlar orta ve 300'ün üzerinde puan alanlar ise yüksek eleştirel düşünme eğilim düzeyine sahip olarak kabul edilmektedir. Alt boyutlarda ise $40^{\prime}$ dan düşük puan alan bireylerin o boyuttaki eleştirel düşünme eğilimleri düşük, puanı 50' den yüksek olan bireylerin ise o boyutta eleştirel düşünme eğilimlerinin yüksek olduğu belirtilmektedir (Kökdemir, 2003). Ölçeğin iç tutarlılık katsayısı .88 (Kökdemir 2003) olarak belirlenmiş olup, bu araştırma kapsamında yapılan analizde .80 olarak hesaplanmıştır.

\subsection{Verilerin Analizi}

Araştırmada "Kişisel Bilgi Formu", "Çevre Etiği Yaklaşımları Ölçeği" ve "Kaliforniya Eleştirel Düşünme Eğilimleri Ölçeği"den elde edilen ham verilerin işlenmesi, çözümlenmesi ve yorumlanması için SPSS 14 paket programından yararlanılmıştır. İstatiksel çözümlemelerde öncelikle örneklem grubunun Kişisel Bilgi Formu'ndaki sorulara verdikleri cevaplar doğrultusunda grubun genel yapısını tanitıcı yüzde ve frekans değerlerine yer verilmiştir. Ayrıca grubun ilgili ölçme araçlarından aldıkları puanların ortalamaları $(X)$, standart sapma (ss) 
ve ölçmenin standart hata (SHx) değerleri hesaplanmıştır. Örneklem grubunu oluşturan öğretmen adaylarının çevre etiği yaklaşımlarının eleştirel düşünme eğilimleri alt boyutlarına göre açıklanıp açılanmadığını (yordanıpyordanmadığını) belirlemek üzere "Çoklu Regresyon Analizi"nden yararlanılmış olup, regresyon analizi modelinde eleştirel düşünme eğilimleri (Analitiklik, Açık fikirlilik, Meraklılık, Kendine güven, Doğruyu arama ve Sistematiklik) yordayıc1/bağımsız değişkenler olarak, öğretmen adaylarının çevre etiği yaklaşımları ise (antroposentrik, biyosentrik ve ekosentrik) yordanan/bağımlı değişkenler olarak belirlenmiştir. Uygulanan Çoklu Regresyon Analizleri sonucunda elde edilen bulguların sunumunda öncelikli olarak yordanan/bağıml değişken ve yordayıcı/bağımsız değişkenler arasındaki ilişki değerleri (r) ile aritmetik ortalama $(X)$, ve standart sapma (ss) değerlerine

yer verilmiştir. Yordayıcı ve bağımlı değişkenler arasındaki ilişkiler Pearson Moment Korelasyon Katsayısı'ndan yararlanılarak hesaplanmıştır. Bağımlı değişkenlerle istatistiksel açıdan anlamlı bir ilişkisi bulunmayan yordayıcı değişkenler regresyon modeline dâhil edilmemiştir. Çalışmada regresyon analizi sonuçları tablolaştırılarak sunulmuştur. Elde edilen istatistiklerin anlamlılığ $\mathrm{APA}$ kriterlerine uygun olarak ,05 düzeyinde çift yönlü olarak sınanmıştır.

\section{BULGULAR}

Araştırmanın bu bölümünde araştırmanın amaçları kapsamında elde edilen verilerin istatistiksel çözümlemelerine ilişkin bilgiler ve bu istatistiksel çözümlemeler sonucunda elde edilen bulgulara yer verilmiştir.

Tablo. 2. Öğretmen adaylarının çevre etiği yaklaşımları ve eleştirel düşünme eğilimlerinin aritmetik ortalama (X), Standart sapma (ss) ve Korelasyon Katsayısı (r) değerleri (N: 641)

\begin{tabular}{|c|c|c|c|c|c|c|c|c|c|c|c|}
\hline $\begin{array}{l}\text { Çevre etiği } \\
\text { yaklaşımları }\end{array}$ & $x$ & ss & 1 & 2 & 3 & 4 & 5 & 6 & 7 & 8 & 9 \\
\hline 1. Antroposentrik & 18.05 & 5.58 & 1 &,$- 246^{* *}$ &,$- 097^{*}$ &,$- 130^{* *}$ & ,026 &,- 069 &,- 010 &,- 026 & $107^{* *}$ \\
\hline 2. Biyosentrik & 49.86 & 3.79 & & 1 &, $334^{* *}$ &, $294^{* *}$ & ,038 & $209^{* *}$ & $108^{* *}$ & $155^{* *}$ & $121^{* *}$ \\
\hline 3. Ekosentrik & 25.66 & 3.44 & & & 1 &, $264^{* *}$ &,- 015 &, $338^{* *}$ & $186^{* *}$ &, 003 &, $080^{*}$ \\
\hline $\begin{array}{l}\text { Eleştirel düşünme } \\
\text { eğilimi }\end{array}$ & 200.52 & 20.35 & & & & & & & & & \\
\hline 4. Analitiklik & 47.84 & 5.46 & & & & 1 &,- 006 &, $519^{* *}$ &, $509^{* *}$ & $123^{* *}$ & $204^{* *}$ \\
\hline 5. Açık fikirlilik & 35.28 & 7.88 & & & & & 1 &,- 007 &,- 002 &, $315^{* *}$ & $424^{* *}$ \\
\hline 6. Meraklılık & 40.01 & 6.06 & & & & & & 1 &, $594^{* *}$ &,- 010 &, $173^{* *}$ \\
\hline 7. Kendine güven & 28.64 & 5.00 & & & & & & & 1 &,- 018 &, $093^{*}$ \\
\hline 8. Doğruyu arama & 23.68 & 5.59 & & & & & & & & 1 & $286^{* *}$ \\
\hline 9. Sistematiklik & 21.94 & 3.86 & & & & & & & & & 1 \\
\hline
\end{tabular}

Tablo.2’ de görüldüğü gibi öğretmen adaylarının çevre etiği yaklaşımlarından Antroposentrik yaklaşım açısından $(x=18.05)$ "katılmıyorum" , biyosentrik $(x=49.86)$ ve ekosentrik $(x=25.66)$ açıdan ise "katılıyorum" seviyesinde oldukları görülmektedir. Elde edilen bu sonuca göre öğretmen adaylarının daha çevreci bir etik yaklaşım içinde olduğu söylenebilir. Yordayııı değişkenler açısından bakıldığında ise öğretmen adaylarının analitiklik ( $x=47.84>40)$ ve meraklılık $(x=40.01>40)$ alt boyutlarını yüksek düzeyde, açı fikirlilik ( $x=35.28<40)$, kendine güven $(x=28.64<40)$, doğruyu arama $(x=23.68<$ $40)$ ve sistematiklik $(x=21.94<40)$ boyutlarının ise düşük düzeyde olduğu tespit edilmiştir. Bununla birlikte adayların toplam eleştirel düşünme eğilimi düzeylerinin de $(x=200.52<240)$ düşük seviyede olduğu belirlenmiştir.

Öğretmen adaylarının çevre etiği yaklaşımları ile yordayıcı değişkenler arasındaki ilişki incelendiğinde ise antroposentrik, biyosentrik ve ekosentrik yaklaşımların üçünün de sistematiklik 
$(\mathrm{r}=.107, \mathrm{r}=.121, \mathrm{r}=.080)$ boyutuyla pozitif yönlü anlamlı ilişkisi olduğu görülürken; analitiklik boyutuyla antroposentrik yaklaşımın negatif yönlü ( $\mathrm{r}=-.130)$, biyosentrik $(\mathrm{r}=.294)$ ve ekosentrik $(\mathrm{r}=.264)$ boyutlarıyla ise pozitif yönlü anlamlı düzeyde ilişkili oldukları görülmektedir. Bununla birlikte biyosentrik çevre etiği yaklaşımı ile meraklılık ( $\mathrm{r}=.209)$, kendine güven $(\mathrm{r}=.108)$ ve doğruyu arama $(r=.155)$ boyutları arasında yine pozitif yönlü anlamlı ilişki olduğu görülmektedir. Ekosentrik çevre etiği yaklaşımı ile de meraklılık $(\mathrm{r}=.338)$ ve kendine güven $(\mathrm{r}=$ .186) boyutları arasında pozitif yönlü anlamlı ilişki olduğu tespit edilmiştir. Diğer yandan her üç çevre etiği yaklaşımı ile açık fikirlilik alt boyutu arasında anlamlı düzeyde bir ilişki tespit edilememiştir.

Tablo.3. Antroposentrik çevre etiği yaklaşımının eleştirel düşünme eğilimleri alt boyutlarına göre yordanıp yordanmadığına ilişkin çoklu regresyon analiz sonuçları

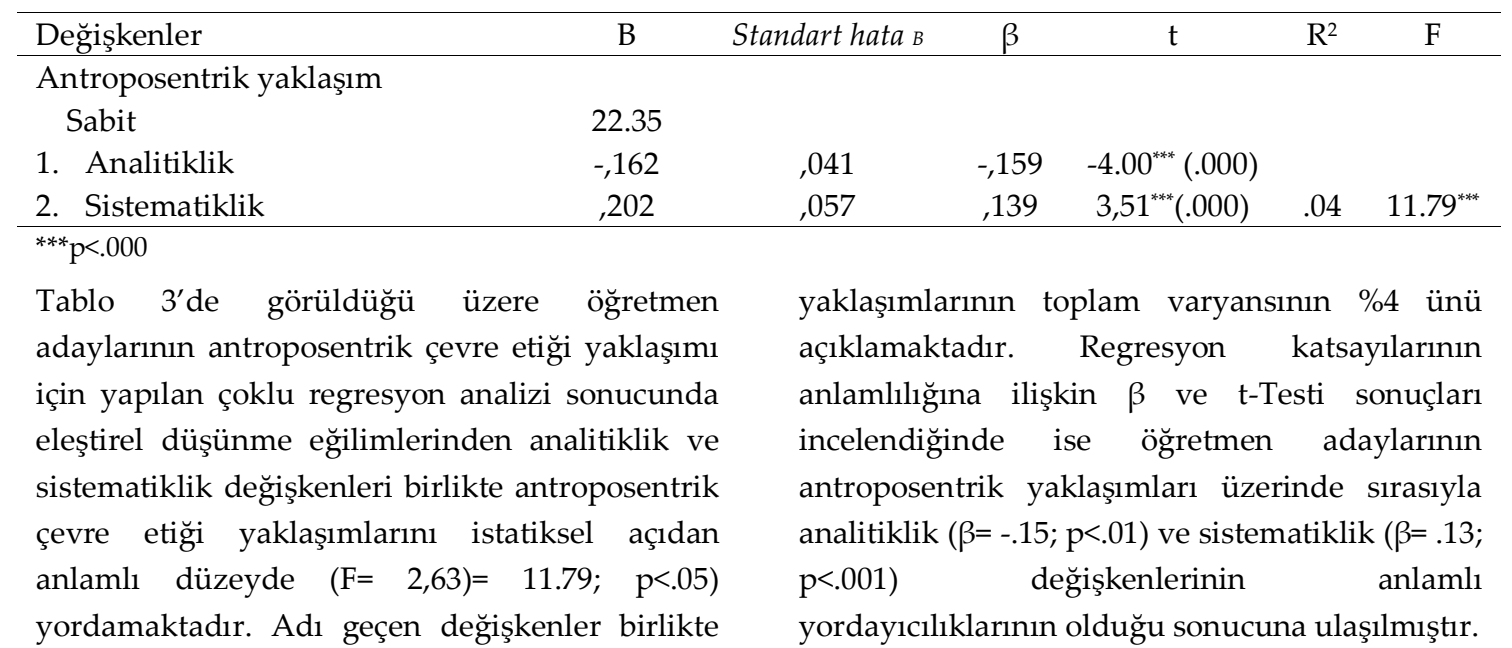
öğretmen adaylarının antroposentrik çevre etiği

Tablo.4. Biyosentrik çevre etiği yaklaşımının eleştirel düşünme eğilimleri alt boyutlarına göre yordanıp yordanmadığına ilişkin çoklu regresyon analiz sonuçları

\begin{tabular}{|c|c|c|c|c|c|c|}
\hline Değişkenler & B & Standart hata в & $\beta$ & $\mathrm{t}$ & $\mathrm{R}^{2}$ & $\mathrm{~F}$ \\
\hline \multicolumn{7}{|l|}{ Biyosentrik yaklaşım } \\
\hline Sabit & 37.28 & & & & & \\
\hline 1. Analitiklik & ,180 & ,032 & .259 & $5.56^{* * *}(.000)$ & & \\
\hline 2. Meraklılık & ,084 & ,031 & .134 & $2,71^{* *}(.007)$ & & \\
\hline 3. Kendine güven &,- 078 & ,037 & -.103 & $-2.123^{*}(.034)$ & & \\
\hline 4. Doğruyu arama & ,079 & ,027 & .117 & $2.976(.003)$ & .11 & $16.307^{* * *}$ \\
\hline 5. Sistematiklik & ,020 & ,039 & .021 &, 52 & & \\
\hline
\end{tabular}

${ }^{* * *} \mathrm{p}<.000,{ }^{* *} \mathrm{p}<.01,{ }^{*} \mathrm{p}<.05$

Tablo 4'de görüldüğü üzere öğretmen adaylarının biyosentrik çevre etiği yaklaşımı için yapılan çoklu regresyon analizi sonucunda eleştirel düşünme eğilimlerinden analitiklik, meraklılık, kendine güven, doğruyu arama ve sistematiklik değişkenleri birlikte biyosentrik çevre etiği yaklaşımlarını istatiksel açıdan anlamlı düzeyde (F 5-635)= 16.30; $\mathrm{p}<.000)$ yordamaktadır. Adı geçen değişkenler birlikte öğretmen adaylarının biyosentrik çevre etiği yaklaşımlarının toplam varyansının \%11 ini açıklamaktadır. Regresyon katsayılarının anlamlılığına ilişkin $\beta$ ve t-Testi sonuçları incelendiğinde ise öğretmen adaylarının biyosentrik yaklaşımları üzerinde sırasıyla analitiklik $(\beta=.25 ; \mathrm{p}<.001)$, meraklılık $(\beta=.13$; $\mathrm{p}<.01)$, kendine güven $(\beta=-.10 ; \quad \mathrm{p}<.05)$ değişkenlerinin anlamlı yordayıcılıklarının olduğu; buna karşın doğruyu arama $(\beta=.11$; $\mathrm{p}>.05)$ ve sistematiklik $(\beta=.021 ; \quad \mathrm{p}>.05)$ 
değişkeninin öğretmen adaylarının biyosentrik yordayıcılığının olmadığı tespit edilmiştir. çevre etiği yaklaşımları üzerinde anlamlı bir

Tablo.5. Ekosentrik çevre etiği yaklaşımının eleştirel düşünme eğilimleri alt boyutlarına göre yordanıp yordanmadığına ilişkin çoklu regresyon analiz sonuçları

\begin{tabular}{|c|c|c|c|c|c|c|}
\hline Değişkenler & B & Standart hata $B$ & $\beta$ & $\mathrm{t}$ & $\mathrm{R}^{2}$ & $\mathrm{~F}$ \\
\hline \multicolumn{7}{|l|}{ Ekosentrik yaklaşım } \\
\hline Sabit & 15.775 & & & & \multirow{5}{*}{.13} & \multirow{5}{*}{$23.28^{* *}$} \\
\hline 1. Analitiklik & ,087 & 029 & 139 & $3.02(.003)$ & & \\
\hline 2. Meraklılık & 173 & ,028 & ,305 & $6,26(.000)$ & & \\
\hline 3. Kendine güven &,- 046 & 033 &,- 067 & $-1,382$ & & \\
\hline 4. Sistematiklik & ,004 & ,034 & ,005 & .12 & & \\
\hline
\end{tabular}

Tablo 5'de görüldüğü üzere öğretmen adaylarının ekosentrik çevre etiği yaklaşımı için yapılan çoklu regresyon analizi sonucunda eleştirel düşünme eğilimlerinden analitiklik, meraklılık, kendine güven, ve sistematiklik değişkenleri birlikte ekosentrik çevre etiği yaklaşımlarını istatiksel açıdan anlamlı düzeyde (F 4- 636) $=23.28 ; \mathrm{p}<.000$ ) yordamaktadır. Adı geçen değişkenler birlikte öğretmen adaylarının biyosentrik çevre etiği yaklaşımlarının toplam varyansının \%13 ünü açıklamaktadır. Regresyon katsayılarının anlamlılı̆̆ına ilişkin $\beta$ ve t-Testi sonuçları incelendiğinde ise öğretmen adaylarının ekosentrik yaklaşımları üzerinde sirasılya meraklılık $(\beta=.30 ; \mathrm{p}<.000)$, analitiklik $(\beta=.13 ; \quad p<.01) \quad$ değişkenlerinin anlamlı yordayıcılıklarının olduğu; buna karşın kendine güven $(\beta=-.06 ; p>.05)$ ve sistematiklik $(\beta=.005$; $\mathrm{p}>$.05) değişkenlerinin öğretmen adaylarının ekosentrik çevre etiği yaklaşımları üzerinde anlamlı bir yordayıcılığının olmadı̆̆ tespit edilmiştir.

\section{TARTIŞMA VE SONUÇ}

Bir yandan çevre sorunlarını yaratırken bir yandan da çevre sorunlarına çözüm getirebilecek en önemli taraf olarak karşımıza çıkan insanoğlunun (Gül, 2013) çözüm üretebilmesi için durumu birçok açıdan değerlendirecek çevreci yaklaşımlara sahip olması gerekir. Bu doğrultuda yapılan çalışma sonuçlarına göre çevre etiği yaklaşımları açısından öğretmen adaylarının biyosentrik ve ekosentrik yaklaşımlarının ( $X=49,56$; $X=25,48)$ yüksek, antroposentrik $(X=18,25)$ yaklaşımlarının ise düşük seviyede olduğu görülmektedir. Bu zıtlık beklenen bir durumdur çünkü antroposentrik yaklaşım sadece insan merkezli iken, diğer iki yaklaşım sadece insan merkezli olmayan yaklaşımları içermektedir. Elde edilen bu sonuçlara göre öğretmen adaylarının çevreci etik yaklaşımları benimsediği söylenebilir. Alan yazında, farklı örneklem grupları ile yapılan çalışmalarda bireylerin çevreci yaklaşımları benimsedikleri tespit edilmiştir (Almeida ve Vasconcelos, 2011; Alnıaçık ve Koç; 2009; Anemiya ve Macer, 1999; Bertoldo, Castro ve Bousfield, 2013; Karakaya ve Çobanoğlu, 2012; Tuncay, 2010; Üstün, Kalkavan ve Gümüşgül, 2014). Bununla birlikte Kortenkamp ve Moore (2001)'nin üniversite öğrencileri yaptı̆̆1 çalışmada ise ekosentrik ve antroposentrik yaklaşımlarının yakın düzeyde olduğu sonucuna ulaşmıştır.

Sorgulamaya dayalı eğitim uygulamalarında özellikle eleştirel düşünme becerisinin önemi ortaya çıkmaktadır. Dolayısıyla çevresel yaklaşımlara yönelik sorgulayıcı bireyler yetiştirmek konusunda da bireylerin eleştirel düşünme eğilim düzeylerinin durumuna bakmak gerekir. Bu amaçla elde edilen bulgulara göre öğretmen adaylarının eleştirel düşünme eğilimlerinin düşük düzeyde olduğu tespit edilmiştir. Bu çalışmada elde edilen sonuçlarla benzerlik gösteren (Hursen ve Kaplan, 2012; Tümkaya, 2011) araştırmalar yanında, yine öğretmen ve öğretmen adayları ile yapılan 
çalışmalarda eleştirel düşüme eğilimleri ve alt boyutları orta düzeyde olduğu sonuçlara da ulaşılmıştır (Çoşkun, 2013; Kartal, 2012; Korkmaz, 2009). Bu çalı̧̧madan elde edilen bulgulara göre eleştirel düşünme eğilimi alt boyutlarına bakıldığında da en yüksek puanın analitiklik boyutunda, en düşük puanın sistematiklik boyutunda olduğu sonucu Tümkaya (2011) ve Korkmaz (2009)'ın yaptıkları çalışma sonuçlarıyla paralellik göstermektedir. Yine elde edilen bulgularda öğretmen adaylarının analitiklik $(x=47.84)$ ve meraklılık $(x=40.01)$ alt boyutlarında orta düzeyde oldukları tespit edilmiştir. Elde edilen bu sonuç öğretmen adaylarının çıkar amacı gözetmeksizin nesnel bir bakış açısına sahip olmaya çalışırken bir yandan da nesnel kanitlar kullanarak problemlerini çözmeye çalışan bireyler olma eğiliminde (Facione ve Facione, 1992; Kökdemir, 2003) oldukları söylenebilir.

Öğretmen adaylarının eleştirel düşünme eğilimleri alt boyutları ve çevre etiği yaklaşımları arasındaki ilişkiye bakıldığında antroposentrik çevre etiği yaklaşımı ile eleştirel düşünme eğilim boyutlarmdan analitiklik alt boyutu ile negatif yönlü, sistematiklik alt boyutuyla arasinda pozitif yönlü bir ilişki olduğu tespit edilmiştir. Diğer bir ifade ile öğretmen adaylarının analitik düşünme eğilimi artıkça antroposentrik yaklaşım eğilimi azalırken, sistematiklik eğilimi arttıkça antroposentrik eğilimin arttığ gözlenmiştir. Ayrıca bu yordayıcı değişkenlerin birlikte öğretmen adaylarının antroposentrik yaklaşımlarını anlamlı bir şekilde açıkladığı ortaya çıkmıştır. Biyosentrik çevre etiği yaklaşımı ile eleştirel düşünme eğilimlerini oluşturan analitiklik, meraklılık, kendine güven, doğruyu arama ve sistematiklik boyutlarının anlamlı ve pozitif yönlü ilişkili oldukları tespit edilmiştir. Diğer bir deyişle öğretmen adaylarının anatiliklik, meraklılık, kendine güven, doğruyu arama ve sistematiklik eğilimleri arttıkça biyosentrik çevre etiği yaklaşımlarının da arttığı saptanmıştır. Bununla birlikte yordayıcı değişkenlerin öğretmen adaylarının biyosentrik yaklaşımlarını anlamlı bir şekilde açıladığı tespit edilmiştir. Buna ek olarak özellikle analitiklik, meraklılık, kendine güven ve doğruyu arama boyutlarının biyosentrik çevre etiği yaklaşımları üzerinde anlamlı yordayıcılıklarının olduğu tespit edilmiştir. Ekosentrik çevre etiği boyutuyla ise eleştirel düşünme eğilimlerinden analitiklik, meraklılık, kendine güven ve sistematiklik alt boyutları arasında pozitif yönlü bir ilişki olduğu tespit edilmiştir. Böylece adaylarının ekosentrik çevre etiği yaklaşımlarının analitiklik, meraklılık, kendine güven ve sistematiklik eğilimleri doğru orantılı olarak artış gösterdiği tespit edilmiştir. Bahsi geçen yordayıcı değişkenlerin birlikte adayların ekosentrik çevre etiği yaklaşımlarını anlamlı bir şekilde yordadığı ortaya konmuştur. Bununla birlikte özellikle analitiklik ve meraklılık eğilimlerinin öğretmen adaylarının ekosentrik çevre etiği yaklaşımları üzerinde anlamlı yordayıcılıklarının olduğu tespit edilmiştir.

Her üç çevre etiği yaklaşımı ile ilişkili olan ve anlamlı yordayıcılık gösteren analitiklik eğilimi öğretmen adaylarının insan merkezli ve insan merkezli olmayan yaklaşımları ayırt ederken mantıksal bir çerçeve ile bakabilmelerini sağladığını göstermektedir. Öznel bir bakış açısıyla bakıldığı takdirde antroposentrik yaklaşımın benimsenmemesi durumu söz konusu olacaktır. Yine elde edilen sonuçlara bakıldığında analitiklik eğiliminin artmasının antroposentrik yaklaşımı azaltırken, biyosentrik ve ekosentrik yaklaşımları azaltması olumlu bir sonuç olarak karşımıza çıkmaktadır. Çünkü insan merkezli antroposentrik yaklaşımın benimsenmesi tersi yöndeki biyosentrik ve ekosentrik yaklaşımların daha yüksek düzeyde olmasını gerektirmektedir. Bir diğer yordayıcı değişken olan Sistematiklik eğiliminin öğretmen adaylarının antroposentrik yaklaşımda anlamlı bir yordayıcısı olduğu tespit edilmiştir. Karmaşık durumlarda akıl yürütme yerine bilgiye dayalı olarak karar verme (Facione ve Facione, 1992; Kökdemir, 2003) becerisini gösteren sistematiklik eğiliminin biyosentrik ve ekosentrik etik yaklaşımları ile de ilişkili olduğu ve öğretmen adaylarının bu yaklaşımları üzerinde etkili olduğu da görülmektedir. Her ne kadar çevre 
etiği yaklaşımları ile sistematiklik eğilim arasında ilişkiler ortaya konmuş olsa da sistematiklik eğiliminin en düşük düzeyde ( $\mathrm{x}=$ 21.94) ortalama göstermesi ayrıca düşündürücü bir durum olarak karşımıza çıkmaktadır. Eğer sistematiklik boyutu geliştirilir ve bireylere bu beceriler kazandırılır ise çevre konusundaki yaklaşımların daha bilimsel, dikkatli ve örgütlü bir bakış açısıyla değerlendirilme yapılarak davranışa dönüştürülmesi mümkün olabilir. Bununla birlikte her üç çevre etiği yaklaşımının da açık fikirlilik alt boyutu ile anlamlı bir ilişki içinde olmadığı görülmektedir. Açık fikirlilik konusunda düşük düzeyde bir sonuç elde edilmesi öğretmen adaylarının farklı yaklaşımlara karşı ön yargılı olmadan kendini değerlendirebilme ve karar vermede mantıklı davranışlar sergileme (Kökdemir, 2003) konusundaki eğilimlerinin yetersiz olduğunu göstermektedir. Bunun yanında çevre etiği yaklaşımları ile açık fikirlilik arasında ilişki olmaması adaylarının özellikle davranışlarını oluştururken farklı görüş ve düşünceleri dikkate almadan karar verdiklerini göstermektedir. Özellikle çevre korumada insanın sadece kendini merkeze almak yerine doğanın bütününü görmesini sağlayacak olan değer yargıların oluşturmada Meraklılık eğiliminin önemli bir yordayıcı olduğu çıkan sonuçlar arasındadır. Bireyin çıkar gözetmeksizin yeni şeyler öğrenme ve bilgi edinme eğilimi çevresel konularda daha doğru değer yargıları oluşturmasında etkili olacaktır. Bununla birlikte bireyin elde ettiği bilgi ve deneyimler sonucunda karar almada kendine güvenini (Facione ve Facione, 1992; Kökdemir, 2003) yansitan eleştirel düşünme alt boyutlarından Kendine güven eğiliminin de yine ekosentrik ve biyosentrik çevre etiği yaklaşımlarının anlamlı bir yordayıcısı olduğu görülmektedir. Dolayısıyla birbirini tamamlayan bu beceriler bir sürecin sonucu olarak doğru etik yaklaşımlara ulaşılmasında etkilidir. Ancak elde edilen sonuçlara göre öğretmen adaylarının antroposentrik yaklaşımlar konusunda bilgi edinme eğilimlerinin anlamlı bir etkisinin olmadığı gözlenmektedir. Aynı şekilde bireyin akıl yürütme sürecine duyduğu güveni yansıtan
(Facione ve Facione, 1992; Kökdemir, 2003) kendine güven eğilimlerinin de antroposentrik yaklaşımı etkilemezken, diğer iki çevre etiği yaklaşımını yordama gücüne sahip olduğu görülmektedir. Dolayısıyla bireylere kazandırılacak bu beceriler doğru yaklaşımların benimsenmesi ve devamında uygun çevresel davranışların gerçekleştirilmesinde önemli bir etkiye sahiptir. Yapılan bazı çalışmalarda bireylerin düşünce ve duygularının uyum içinde olmayıp, çevreci bir yaklaşıma sahipken davranışlarında bunu göstermedikleri tespit edilmiştir. Misfud (2011)'in ortaöğretimi bitirmek üzere olan öğrencilerle yaptığ çalışmada; çevreye yönelik güçlü pozitif tutum içinde olduklarını ancak çevreye yönelik çok az pozitif eylemde bulunduklarını belirlemiştir. Benzer şekilde Rebolj ve Devetak (2013)' ün 7. sınıf öğrencileri ile yaptıkları çalışmada öğrencilerin çoğunun kuraklık, susuzluk gibi çevre konularında endişe duyarken, çevre projelerine katılım konusunda istekliliğin çok fazla gerçekleşmediğini gözlemişlerdir. Liu, Liang, Fang ve Tsai (2015)' nin yaptıkları araştırmada da öğretmenlerin çevreye yönelik bilgi ve tutumlarının iyi düzeyde olduğunu ancak eylemsel açıdan düşük seviyede olduklarını tespit etmişlerdir. Bu sonuçların ise çoğunlukla geleneksel bir şekilde özellikle fen programlarında verilen eğitimden kaynaklandığı ifade edilmektedir. Bu durumda çevre eğitimi ve çevre etiği programlarının geleneksel anlayışın ötesinde bireyin toplum ile çevre arasındaki çelişkili durumunu ortadan kaldırarak problemleri çözebilecek (Barr, 2003) bireyler yetiştirme içeriğine sahip sorgulamaya dayalı, üst düzey zihinsel becerileri kullanan ve sadece okul değil okul dışı uygulamaların gerçekleştirildiği şekilde düzenlenmesi gereği ortaya çıkmaktadır. Burada sosyal davranış kazanımlarının etkisi düşünülmelidir. Bazı araştırmalarda (Liu, Liang, Fang ve Tsai, 2015; Mifsud, 2011; Rebolj ve Devetak, 2013) ortaya çıkan sonuçlarda çevreye yönelik pozitif tutum, ilgi ya da yaklaşım eğiliminin yeterli düzeyde olsa bile davranışa dönüştürme konusunda olumlu sonuçlar elde edilmediği belirtilmektedir. 
Dolayısıyla elde edilen bu sonuçlar ışığında üst düzey düşünme becerileri dikkate alınarak oluşturulan çevre eğitimi programları sadece çevreye yönelik olumlu tutum, etik yaklaşım ya da değer kazandırmanın yanında sahip olunan bilgi, beceri ve tutumların davranışa dönüştürülmesi de sağlanmalıdır.

Yine bu çalışma kapsamında elde edilen bulgulara göre birbirinden farklı düşünceleri analiz ederken, gerçeği aramak amacıyla sorular sormak ve farklı düşünceleri bile değerlendirirken subjektif bakış açısına sahip olabilme eğilimini (Facione ve Facione, 1992; Kökdemir, 2003) gösteren Doğruyu arama eğiliminin sadece canlı merkezli biyosentrik çevre etiği yaklaşımı ile ilişkili olduğu çıkan sonuçlar arasındadır. Özelikle farklı düşünceleri eleştirirken doğru davranış biçimi sergileme ve dolayısıyla kendi çıkarlarının tersi olan çevreci yaklaşımlara karşı doğru analiz etme becerisinin (Facione ve Facione, 1992; Kökdemir, 2003) sadece biyosentrik yaklaşımda olduğu görülmektedir. Ortaya çıan bu sonuca göre öğretmen adaylarının duygusal bir eğilimle davranış sergileyerek canlıları ayırt etmeye çalıştıkları söylenebilir.

Her ne kadar elde edilen sonuçlarda adayların eleştirel düşünme eğilimleri genel olarak düşük çıksa da ortaya çıkan çevre etiği yaklaşımları ve eleştirel düşünme eğilimleri arasındaki ilişkiler göz önünde bulundurulmalıdır. Dolayısıyla ortaya çıkan bu sonuçlar ışığında etik yapının kodları veya davranış kuralları dikkate alınarak, öğrenenlerin öğrenme süreçlerinin eleştirel düşünme ve araştırmaya dayalı gerçekleştirildiği bir süreçle gerçekleşmesinin (Shapiro ve Takacs, 2004) uygun olduğu görülmektedir. Eleştirel düşünme eğiliminin kişinin problem çözme, düşünceleri değerlendirme veya karar verme becerilerinde etkili bir faktör (Giancarlo ve Facione, 2001; Lipman 2003; Tsui, 2002) olduğu ifade edilirken, düşük eleştirel düşünme eğiliminde olan öğrencilerin eleştirel düşünme aktivitelerinde düşünce, değer, inanış veya diğer öğrencilerle işbirliği konusunda sınıf aktivitelerine katılım konusunda zayıf oldukları belirtilmektedir (Quinn, 2012; Seferoğlu ve Akbıyık, 2006; Türnüklü ve Yeşildere, 2005). Birçok araştırmacı ve eğitimci, eğitimde yüksek önceliklerden biri olarak eleştirel düşünmenin önemine vurgu yapmakta (Dressel ve Mayhew, 1954 aktaran Burris ve Garton, 2006; Ennis, 1987) ve çevre ve doğal kaynaklarla ilişkili eğitimlerin küresel ekonomide önemli bir ihtiyaç olduğunu ve bununda eleştirel düşünme becerilerinin geliştirilmesini içeren eğitim programlarının artırılması ile gerçekleştirilebileceği belirtilmektedirler (Jones and Merritt, 1999; Quinn, 2012). Turan ve Aydın (2013) yaptıkları çalışmada eleştirel düşünme becerileri öğretimine dayalı hazırladıkları öğretim modeli ile biyoloji öğretmen adaylarının ekolojik paradigma eğilimlerinin olumlu yönde artış gösterdiği tespit edilmiştir. Bu sonuca göre eleştirel düşünme becerilerine uygun hazırlanan programların ekosentrik yaklaşımları benimsemek konusunda etkili olabileceği söylenebilir. Özellikle grup tartışmalarının olduğu, soru ve sorunlara kendi kendine cevap verebilecek üst düzey becerileri kullanabilecek program içerikleri ve bunları gerçekleştirebilecek öğretmen eğitiminin gerçekleştirilmesi gerekir. Sadece bir konu içinde değil bütün program ve içeriklere entegre edilmiş çevre eğitimi programları oluşturulmalıdır (Kimaryo, 2011; Pavlova, 2015).

Çevre etiğinin temel amacı insan ve çevre arasındaki ilişkinin üstesinden gelmeye çalışırken, çevre etiği eğitiminin amacı bireyin seçme, karar verme ve harekete geçirme becerilerinin kazanmasını sağlar. Çevre eğitimi süresince bireyler özellikle tartışmaya yöneltilerek sadece kavram oluşturulması değil asıl önemli olan içselleştirmeyi gerçekleştirmesi sağlanabilir. Bu yüzden özellikle eğitimciler olarak çevreye yönelik değer sisteminin oluşmasını sağlayacak ortamlar sağlamamız gerekir. Bireyin çevreye yönelik davranışlarını yönetebilmesi ve bu sırada duyarlı ve doğru etik davranışları geliştirebilmesi çevre eğitimi ile gerçekleştirilebilir (Raı ve Sırma; 2011). Bunların gerçekleşmesi çevre etiği ile ilgili pedagojik bilgi ve içeriğe sahip ve uygun stratejilerin 
uygulandığı öğretim biçimlerinin uygulanması ile elde edilebilir. Dolayısıyla bu sürecin yönetiminde önemli bir paydaş olan öğretmen ve öğretmen adaylarının etik bakış açıları ve bu bakış açısını oluştururken nasıl bir düşünce biçiminde hareket ettikleri önem kazanmaktadır. Çevre etiği konusunda çok fazla yorum ve tanımlama olması yanında özellikle günlük eylemlerdeki karar verme konusunda çok fazla ilerleme kaydedilmiş değildir. Walsh ve Paul (1998) öğrencilerin eleştirel düşünme becerilerini geliştirmek için öncelikle öğretmenlerin hem hizmet öncesi hem de hizmet içinde yetiştirilmesi ile mümkün olabileceğini belirtmektedir. Dolayısıyla öğretmenlerin yetiştirecekleri bireylerde analitik düşünmeyi geliştirmeye ve bu düşünme sistemini kullanarak daha çevreci bir yaklaşımı benimseme ve davranışa dönüştürmeye dayalı mesleğin gerektirdiği yeterlilikleri kazanabilmesi için öğretmen yetiştiren kurumların programlarının ilgili yeterlilikleri kazandırılacak şekilde düzenlenmesi gerekmektedir.

\section{Reference}

Alnıaçı, Ü., Koç, F. (2009). Yeni Çevresel Paradigma Ölçeği İle Üniversite Öğrencilerinin Çevreye Yönelik Tutumlarının Değerlendirilmesi. Balıkesir Üniversitesi Burhaniye MYO Bölgesel Kalkınma Kongresi. 14 - 16 Kasım. BALIKESİR. 173- 185.

Almeida, A., Vasconcelos, C. (2013). Teachers' Perspectives on the Human- Nature Relationship: Implications for Enviromental Education. Research in Science Education, 43(1), 299- 316.

Anemiya, K., Macer, D. (1999). Enviromental Education and Enviromental Behaviour in Japanese Students. Eubios Journal of Asian and International Bioetics, 9, 109- 115.

Barr, S. (2003), Strategies for sustainability: citizens and responsible environmental behaviour. Area, 35: 227-240. doi:10.1111/1475-4762.00172

Bertoldo, R., Castro, P., Bousfield, A. B. S. (2013). Pro-Environmental Beliefs and Behaviors: Two Levels of Response to Environmental Social Norms. Revista Latinoamericana de Psicología, 45(3), 435-446.

Burris, S., Garton, B. L. (2006). An Investigation of The Critical Thinking Ability of Secondary Agriculture Students. Journal of Southern Agricultural Education Research, 56(1), 18- 29.

Cochrane, A. (2006). Environmental ethics. Internet Encyclopedia of Philosophy . ISSN 2161-0002. http://eprints.lse.ac.uk/21190/ (11.09.2008-11.37)

Çepni, S.(2010). Araştırma ve Proje Çalışmalarına Giriş. (5. Baskı), Trabzon.

Çoşkun, M.K. (2013). Din Kültürü ve Ahlak Bilgisi Öğretmen Adaylarının Eleştirel Düşünme Eğilimleri (İlahiyat- Eğitim DKAB Karşılaştırılması). Atatürk Üniversitesi Sosyal Bilimler Enstitüsü Dergisi, 17(1), 143- 162.

Demirel, Ö. (2004). Eğitimde Program Geliştirme. Ankara, Pegem A Yayıncllı.

Dressel, P. L., Mayhew, L. B. (1954). General education: Explorations in evaluation. Washington, D.C. American Council on Education.

Educational Frameworks For Environmental Ethics. (2012). Draft report for working group 11 of the Ethics and Climate Change in the Asia Pacific (ECCAP) Project.

Ennis, R.H. (1987). A taxonomy of critical thinking dispositions and abilities. In J. Baron \& R. Sternberg (Eds.), Teaching thinking skills: Theory and practice. New York: W.H. Freeman.

Ennis, R. H. (1993). Critical thinking assessment. Theory into Practice, 32 (3), 179-186.

Ertan, B. (2004). 2000' li Yıllarda çevre etiği yaklaşımları ve Türkiye. Yönetim Bilimleri Dergisi, 3(1), 93108.

Facione, P. A., Facione, N. C. (1992). The California Critical Thinking Dispositions Inventory (CCTDI); and the CCTDI Test manual. Millbrae, CA: California Academic Press. 
Facione, P.A., Facione, N.C., Giancarlo, C.A.F. (1998). The California Critical Thinking Disposition Inventory. California: Academic Press.

Giancarlo C.A, Facione P.A. (2001). A look across four years at the disposition toward critical thinking disposition among undergraduate students. The Journal of General Education, 50(1), 29-55.

Gök, B., Erdoğan, T. (2011). The Investigation of The Creative Thinking Levels and The Critical Thinking Disposition of Pre-Service Elementary Teachers. Ankara University, Journal of Faculty of Educational Sciences, 44 (2), 29-51.

Gül, F. (2013). İnsan-Doğa İlişkisi Bağlamında Çevre Sorunları Ve Felsefe. Pamukkale Universitesi Sosyal Bilimler Enstitüsü Dergisi, 14, 17-21

Halonen, J., Gray, C. (2001). The critical thinking companion for introductory psychology. New York: Worth Publishers.

Halpern, D. F. (1998). Teaching Critical Thinking across Domains: Dispositions, Skills, Structure Training, and Metacognitive Monitoring. American Psychologist, 53(4), 449-455.

Hargrove, E. (2000). Toward Teaching Environmental Ethics: Exploring Problems in the Language of Evolving Social Values. Canadian Journal of Environmental Education, 5, 114- 133.

Hursen, Ç., Kaplan, A. (2012). The Determination of The Critical Thinking Tendencies of Teacher Candidates. Cypriot Journal of Educational Science, 7(3), 196- 207.

Huying, X. (2004). Humankind Takes up Environmental Ethics. Chinese Education And Society, 37 (4), 1623.

Jardin, J. R. D. (2006). Çevre Etiği, Çevre Felsefesine Giriş. (Çev. Ruşen Keleş). İmge Kitabevi, Ankara.

Jones, P. C., J. Q. Merritt. 1999. Critical thinking and interdisciplinarity in environmental higher education: The case for epistemological and values

awareness. J. Geog. High. Ed. 23:349-357.

Karalı, Y. (2012). Eğitim Fakültesi Öğrencilerinin Eleştirel Düşünme Eğilimleri (İnönü Üniversitesi Örneği). Yayınlanmamış Yüksek Lisans Tezi. İnönü Üniversitesi, Eğitim Bilimleri Enstitüsü, Eğitim Programları Ve Öğretim Bilim Dalı. Malatya.

Karakaya, Ç., Çobanoğlu, E. O. (2012). The Viewpoints of Education Faculty Last Grade Students about the Environment according to Anthropocentric and Nonanthropocentric Approaches. Journal of Turkish Science Education, 9 (3), 36- 39.

Karasar, N. (2000). Bilimsel Araştırma Yöntemi. (10. Basım). Ankara: Nobel Yayın Dağıtım.

Karatekin, K., Aksoy, B. (2012). Sosyal Bilgiler Öğretmen Adaylarının Çevre Okuryazarlık Düzeylerinin Çeşitli Değişkenler Açısından İncelenmesi. Turkish Studies - International Periodical For The Languages, Literature and History of Turkish or Turkic, 7(1), 1423-1438.

Kartal, T. (2012). İlköğretim Fen Bilgisi Öğretmen Adaylarının Eleştirel Düşünme Eğilimlerinin İncelemesi. Ahi Evran Üniversitesi Kırşehir Eğitim Fakültesi, 13(2), 279- 297.

Kılıç, S. (2008). Çevre Etiğĭ, Orion Yayınları, Ankara.

Kimaryo, L., A. (2011). Integrating Environmental Education in Primary School Education in Tanzania, Teachers' Perceptions and Teaching Practices. Åbo Akademı Unıversity Press

Kogut, L. S. (1996). Critical Thinking in General Chemistry. Journal of Chemical Education, 73(3), 218,

Korkmaz, Ö. (2009). Öğretmenlerin Eleştirel Düşünme Eğilim ve Düzeyleri. Ahi Evran Üniversitesi Kırşehir Eğitim Fakültesi Dergisi, 10(1), 1- 13.

Kortenkamp, K. V., Moore, C. F. (2001). Ecocentrism And Anthropocentrısm: Moral Reasonıng About Ecological Commons Dilemmas. Journal Of Environmental Psychology, 21(1). 1- 12.

Kökdemir, D. (2003). Belirsizlik Durumlarında Karar Verme ve Problem Çözme. Ankara Üniversitesi, Sosyal Bilimler Enstitüsü, Yayımlanmamış Doktora Tezi, Ankara.

Lipman, M. (1988). Critical Thinking-What Can It Be? Educational Leadership, September, 38- 43.

Lipman, Matthew (2003). Thinking in Education, Cambridge: Cambridge University. 
Liu, S. Y., Yeh, SS. C., Liang, S. W., Fang, W. T., Tsai, H. M. (2015). A National Investigation of Teachers' Environmental Literacy as a Reference for Promoting Environmental Education in Taiwan. The Journal of Enviromental Education. 46 (2), 114- 132.

Mifsud, M. C. (2011). An Investigation on the Environmental Knowledge, Attitudes and Behavior of Maltese Youth. US-China Education Review, 3, 413-422.

Ojomo, P. A. (2011). Environmental ethics: An African understanding. African Journal of Environmental Science and Technology. 5(8), 572-578.

Quinn, C. (2012). Studies on Critical Thinking for Environmental Ethics Presented to the Faculty of The Graduate College at the University of Nebraska. In Partial Fulfillment of Requirements For the Degree of Doctor of Philosophy, Lincoln, Nebraska.

Özden, Y. (2005). Öğrenme ve Öğretmen. Pegem A Yayıncllık, Ankara.

Paul, R, W., Elder, L., Bartell, T. (1997). California Teacher Preparation for Instruction in Critical Thinking: Research Findings and Policy Recommendations. California Commission on Teacher Credentialing Sacramento, California.

Paul, R., Elder, L. (2006). Critical thinking: the nature of critical and creative thought. Journal of Developmental Education, 30 (2), 34-35.

Paul, R., (1993). The Logic of Creative and Critical Thinking. The American Behavioral Scientist (19861994), 37(1), 21-39.

Pavlova, M. (2015). Design and tecnology for sustainable futures: In preparation for global citizenship. (Eds. Kay Stables, Steve Keirl). Enviroment, Ethics and Cultures. International Technology Education Series. Sense Publishers. Rotterdam, Netherlands. 87- 100.

Pithers, R.T., Soden, R. (2000). Critical thinking in education: a review. Educational Research, 42, (3), 237349.

Ra1, A.K., Surma, R.N. (2011). Environmental Ethics Education : A Necessity To İnitiate Environment Oriented Action. Shaikshik Parisamvad, An International Journal of Education (SPIJE). 7 (1), 33- 37.

Rebolj, N., Devetak, I. (2013). 12-Year-Old Students' Attıtude Towards And Views About The Environmental Problems. European Science Education Research Association, ESERA e_Book_2013.

Roth C.E. (1992). Environmental literacy: its roots, evolution and directions in the 1990s,

Saka, M., Sürmeli, H. (2013). Development of a Scale for Environmental Ethics Approaches. A Study of Validity and Reliability. Journal of Environmental Protection and Ecology JEPE. 14(3A), 1443-1452.

Sandler, R. (2007). Character and Environment. New York: Columbia University Press.

Seferoğlu, S., Akbıyık, C. (2006). Eleştirel Düşünme Ve Öğretimi. Hacettepe Üniversitesi Eğitim Fakültesi Dergisi,30,193- 200.

Sürmeli, H., \& Saka M. (2013). Preservice teachers' anthropocentric, biosentric and ecocentric environmental ethics approaches. Internaional Journal of Academie Research, 5(5), 159 - 163.

Shapiro,D. F., Takacs, D. (2004). A pragmatic, co-operatıve approach to teaching environmental ethics. Worldviews: Global Religions, Culture, and Ecology. 8(2), 243 - 266.

Schoen, D. (1983). The reflective practitioner. San Francisco: Jossey-Bass

Seferoğlu, S.S., Akbıyık, C. (2006). Eleştirel Düşünme ve Öğretimi (Teaching Critical Thinking). Hacettepe Üniversitesi Eğitim Fakültesi Dergisi (H.U. Journal of Eucation) 30, 193-200.

Sternberg, R. J. (1986). Critical Thinking: Its Nature, Measurement and Improvement. Yale University. ERIC.

Suhane, A. (2012). Environmental Ethics of In-service Teachers, Pre-service Teachers and Teacher Educators. Rajeev Gandhr College Research Journal, Research Scapes (An International Multi Disciplinary Journal, 1(1), 1-9. 
Tsui, L. 2002. Fostering critical thinking through effective pedagogy: Evidence from four institutional case studies. J. High Ed. 73:740-763.

Tuncay, B. (2010). Moral Reasoning Of Pre-Service Science Teachers Toward Local And Non-Local Environmental Problems. Department of Elementary Science and Mathematics Education. Yayınlanmamış Yüksek Lisans Tezi. ODTÜ, Ankara.

Turan, S., Aydın, H. (2013). Eleştirel Düşünme Becerilerini Temel Alan Biyoloji Eğitiminin Ortaöğretim Öğrencilerinin Ekolojik Etik Yaklaşımlarına Ve Eleştirel Düşünme Eğilimlerine Etkisi. E-Journal of New World Sciences Academy. NWSA-Education Sciences. NWSA-Education Sciences, 1C0584, $8,(2), 232-244$.

Türnüklü, E., Yeşildere, S. (2005). Türkiye'den Bir Profil: 11-13 Yaş Gurubu Matematik Öğretmen Adaylarının Eleştirel Düşünme Eğilim ve Becerileri. Ankara Üniversitesi Eğitim Bilimleri Fakültesi Dergisi, 38( 2), 167-185

Tümkaya, S. (2011). Fen Bilimleri Öğrencilerinin Eleştirel Düşünme Eğilimleri Ve Öğrenme Stillerinin İncelenmesi. Ahi Evran Üniversitesi Eğitim Fakültesi Dergisi,12(3),215-234.

Uygun, S., (2006). "Çevre Sorunlarının Küreselleşmesi, Etiği ve Eğitimi”, Felsefe Eğitim Sanat Saffet Bilhan Armağanı (Hazırlayanlar: S. Büyükdüvenci ve V. Taşdelen), 279- 290, Ankara, Hece Yayınları.

Ünal, N. (2008). Pre-Sevice Teacher's Perceptıons Toward Global Versus Local Environmental Issues. The Department Of Elementary Scıence And Mathematıcs Educatıon. Yayınlanmamış Yüksek Lisans tezi. ODTÜ, Ankara.

Üstün, Ü. D., Kalkavan, A., Gümüşgül, O. (2014). An investigation of Students' Attitudes on the Enviroment: The Influenceon Participation in Outdoor Recreation. International Journal of Sport Studies. 4(9), 1109- 1113.

Yaylı, H., Çelik, V. (2011). Çevre Sorunlarının Çözümü İçin Radikal Bir Öneri: Derin Ekoloji. A Radical Suggestion for the Solution of Environmental Problems: Deep Ecology. Selçuk Üniversitesi Sosyal Bilimler Enstitüsü Dergisi. 26, 369- 377.

Walsh, D., Paul, R. (1998). Thegoal of critical thinking: from educational ideal to educational reality. Washington, D.C. : American Federation of Teachers.

Zascavage, V., Masten, W. G., Schroeder-Steward, J., Nichols, C. (2007). Comparison of critical thinking in undergraduates and graduates in special education. International Journal of Special Education, $22,25-31$. 


\section{EXTENDED SUMMARY}

Relationship between human and environment as well as the type and extent of this relationship have gained importance with increasing environmental problems in recent years. We accordingly face the issue of environmental ethics approach which is a critical component of the individual's attitude and behavior towards the environment. Environmental ethics is a sub-branch of applied ethics, questioning how human's relationship with the outer world should be in an effort to determine correct behavior type (Amerbauer, 1998 cited by Kılıç, 2008). Applied ethics gained a scientific identity particularly in 1980 's around debates on the existence of an environmental crisis (Cochrane, 2006) and there are various environmental ethics perspectives. Environmental ethics has three basic approaches. Anthropocentric environmental approach considers non-human natural beings only for the benefit of humans while biocentric approach has granted rights to both human and non-human beings. Another environmental ethics approach, ecocentrism represents the broadest ethical understanding that involves every animate and inanimate being in the world. Every being in the world is a part of a consistent system. Maintenance of this system and increasing the number of individuals sensitive to autonomy of all animate and inanimate beings in the world (ecocentric, biocentric) is important for sustainability and livability of the world. Negative approaches of individuals mean that they do not recognize species, ecosystems and other living beings' right to live.

Establishment of these thinking systems depends on to what extent individuals possess critical perspective, defined as deciding what to believe and assuming its responsibility. Considering that life long learning is continuously emphasized in contemporary education, it has become more necessary than ever that individuals possess critical thinking capacity which influences their problem solving skills and creativity (Seferoğlu and Abıyık, 2006). Teachers have to possess these skills before other individuals. They must adopt critical thinking in their own lives in order to make students acquire these skills (Özden, 2005; Demirel, 2004).

Environmental perspectives of adults and teachers in particularly should not be neglected in this educational process that goes on from family to school. It should also not be forgotten that critical perspective is as important as knowledge in having a consciousness that may cause a change of behavior. Teachers play a critical role in revealing positive environmental perspectives of individuals. Relationship between teachers' environmental approach and extent of their critical thinking skills must be considered for individuals to make correct decisions and appropriate behavior related to the environment.

Therefore, the goal of this study is to examine preservice teachers' critical thinking dispositions on their environmental ethics approaches (anthropocentric, biocentric, ecocentric). Thus, authors sought answers to three questions: (1) What are the extent of preservice teachers' environmental ethics approaches? (2) What are the level of their critical thinking disposition?" and (5) "Do critical thinking dispositions predict their environmental ethics approaches?" Study model is relational screening model. Study population involves 641 preservice teachers who are studying science, preschool and primary school teaching at teacher training faculties of two state universities. Data collection tools are Environmental Ethics Approaches Scale (Saka, Sürmeli 2013) and California Critical Thinking Disposition Inventory (Kökdemir, 2003). Questions were also asked to obtain personal information of preservice teachers. While forming the study groups, author considered that preservice teachers should not have taken environment courses during their graduate training.

Data was analyzed on SPSS 14 program to calculate percentile, frequency, average, standard deviation and standard error. "Multiple Regression Analysis" was used in order to find out whether environmental ethics approaches of preservice teachers in study sample are predicted with regards sub- 
dimensions of critical thinking disposition. In Multiple Regression Analysis, critical thinking dispositions (Analyticity, Open-mindedness, Inquisitiveness, Self-confidence, Truth- seeking, Systematicity) were determined as predictive/independent variables while pre service teachers' environmental ethics approaches (anthropocentric, biocentric and ecocentric) were determined as predicted/dependent variables. Presentation of the findings of Multiple Regression Analysis involved relational values $(\mathrm{r})$, average $(\mathrm{X})$ and standard deviation (ss) between predicted/dependent variables and predictive/independent variables. Relations between predictive and dependent variables were calculated with Pearson Moment Correlation Coefficient. Regression model did not include those predictive variables that had no significant relation with dependent variables. Regression analysis results were presented on tables. Significance of the statistics was tested at, 05 level in accordance with APA criteria.

The analysis showed that preservice teachers had strong biocentric and ecocentric approaches and poor anthropocentric approach. Authors found out poor level of critical thinking disposition among preservice teachers. They also found out that level of analyticity and inquisitiveness was moderate. When it came to the main issue of the study that focused on whether preservice teachers' critical thinking dispositions predicted their environmental ethics approaches, analysis showed that analyticity aspect of their critical thinking disposition predicted all three environmental ethics approaches. On the other hand, it was found that several other critical thinking dispositions also predicted various environmental ethics approaches but open-mindedness did not predict any environmental ethics approaches. Findings show that preservice teachers' critical thinking disposition level is poor and these dispositions predict environmental ethics approaches. Thus, it is recommended that teacher training programs prioritize developing critical thinking dispositions and skills of candidate teachers and environmental training programs develop environment-related awareness, interest and attitude in addition to taking steps in problem solving and behavior change through critical thinking skills. 